\title{
INDUCTION OF CALLUS FROM DIFFERENT EXPLANTS OF Bacopa monnieri AND EFFECT OF ADJUVANT ON THE GROWTH RATE OF THE CALLI
}

\author{
RITIKA KUMARI ${ }^{1}$ \\ Research Fellow in Botany, Department of Botany, B.R. Ambedkar Bihar University, Muzaffarpur, Bihar, India
}

\begin{abstract}
Present work was carried out to observe the impact of growth regulators the auxin and cytokinin to observe their combined impact on callus induction and these calli were subcultured in the presence of adjuvant, here coconut milk to observe its impact on the growth rate of the calli. During the work it was noted that all the explants such as young leaf, mature leaf, and the internodes responded to different concentrations of 2,4-D and Kinetin, but highest percentage of response for swelling and callus induction was noted in the mature leaf explants when it was inoculated in MS + $1.5 \mathrm{mg} / \mathrm{l} 2,4-\mathrm{D}+0.4 \mathrm{mg} / \mathrm{l} \mathrm{Kinetin}$ that was 94.68 and 90.34 respectively. This was followed by the internodal explants in the same medium and the percentage of response was 88.72 for swelling the and $\mathbf{7 8 . 5 0}$ for callus induction. Here minimum response was in young leaf explants for swelling 78.25 and for callusing 73.46 respectively. Similar trends of response were noted in case of all the explants cultured in the medium supplemented with $1.0 \mathrm{mg} / \mathrm{l}$ 2,4-D + $3 \mathrm{mg} / \mathrm{l} \mathrm{Kinetin.} \mathrm{Callus} \mathrm{raised} \mathrm{from} \mathrm{mature} \mathrm{leaf} \mathrm{in} \mathrm{MS} \mathrm{+} \mathrm{1.5} \mathrm{mg/l} \mathrm{2,4-D} \mathrm{+} \mathrm{0.4} \mathrm{mg/l} \mathrm{Kinetin,} \mathrm{was} \mathrm{subcultured} \mathrm{in}$ the same medium with coconut milk as adjuvant, in the ratio of $0.5 \%, 1.0 \%$ and $1.5 \%$ which was $5 \mathrm{ml} / \mathrm{l}, 10 \mathrm{ml} / \mathrm{l}$ and $15 \mathrm{ml} / \mathrm{l}$. After three weeks the growth rate $\&$ biomass were calculated. It was observed that MS + 1.5 mg/l 2,4-D + 0.4 mg/l Kinetin and 1.5\% coconut milk promoted better growth as was noted from the diameter and fresh weight of the calli in subculture. Here, the growth response, growth rate and weight of the calli were lowest in the medium containing $0.5 \%$ coconut milk.
\end{abstract}

KEYWORDS: Bacopa monnieri, Adjuvant, Coconut Milk, Sub Culture, Swelling, Explants, Diameter, Fresh Weight

ABBREVIATIONS: 2,4-D = 2, 4- Dichlorophenoxy Acetic Acid; KN = Kinetin; $\mathrm{CM}=$ Coconut Milk

Bacopa monnieri (L.) Pennel, commonly called as 'Brahmi' in local language, belong to the family Serophulariaceae. At Muzaffarpur plants are found from late June to October in wild population. They are generally found in moist shady places and due to their vigorous branching they form a mat like structure on the ground. They may grow in submerged conditions and the among the green leaves white flowers may attract anybody towards it. In addition to normal tap roots, several adventitious roots may be found at each node which is in touch of soil.

Bacopa monnieri (L.) Pennel, was placed second in priority list of the most important medicinal plants evaluated on the basis of their medicinal importance, commercial value and potential for further research and development (Shrivastva et al., 1999). Tripathi et al; (1996) reported that it acts as an antioxidant that stimulates brain circulation and also enhances the serotonin level in disorders, reducing stress. Mehta, (2017) reported that it is also used to treat asthma, insanity, epilepsy, hoarseness, enlargement of spleen, against snake bite, to cure rheumatism, leprosy, eczema and other skin diseases. Ti has been used as brain tonic in Ayurvedic system of medicine to improve memory, concentration, and learning as well as to cure metal illness (Srivastva et al., 1999). Presence of most important Saponins such as Bacoside A, B, C, and D in Bacopa monnieri has been reported by Majumdar et al., (2011), Ahire et al., (2013). Here Bacoside A is being used for the production of memory enhancing capsule. Ali et al., (2001), Shukla et al., (2007) reported that Bacopa monnieri is being used in phytoremediation of Heavy metal such as Cadmiumm, Mercury \& Chromium.

Tissue culture studies for micropropagation and callus regeneration have been done by Arumugam and Bhojwani (1990), Rani and Grover (1999), Martin (2004), Tsay Hsin-Sheng and Agarwal, (2005), Wood Ward and Bartel (2005), Sakakibara (2006), Bahadur et al., (2007), Chaturvedi et al., (2007), Monga et al., (2008), Wang et al., (2008), Siva et al., (2009), Dash and Mandal (2010), Joshi et al., (2010), Juan et al., (2010), Showkat et al., (2010), Ahmad et al., (2011), Madhulkar et al., (2011), Rao et al., (2011), Rout et al., (2011), Subashri and Kolipillai (2012), Jayakumar and Lingam (2013), Kalsaitkar et al., (2014), Kaur et al., (2013), Osman et al., (2013), Sundriyal et al., (2013), Kumari Ritika et al., (2014), Subhashri and Pillai (2014), Thangavel et al., (2014), Anita (2017), Aradkani et al., (2017), Abiri et al., (2017), Khattak et al., (2017), Rajeev et al., (2018) and Srivastva et al., (2017). In the 
present work impact of plant growth regulators \& adjuvant on the growth of callus have been studied.

\section{MATERIALS AND METHODS}

The material used and methods followed to carry out the experiments have been described below.

\section{Location for the Plants}

Bacopa monnieri (L.) was located in the campus of University Department of Botany, B.R. Ambedkar Bihar University, which was growing in wild habitat. The place was marked and unwanted weeds were removed from the surrounding of the plant which was present in a small area.

\section{Preparation of the Explants}

Healthy branches from the plant of Bacopa monnieri were carefully excised with the help of presterilized sharp blade. This was placed in a beaker containing distilled water and brought to the laboratory. Braches were taken out form the beaker and were placed in a wide mouth $2 \mathrm{~L}$ conical flask. The mouth was covered with the muslin cloth with the help of rubber bands. It was placed under running tap water. The materials were circulating within the flask but due to muslin cloth they were not coming out along with outgoing water current. This was done for 40 minutes so that the dust particles were washed away.

Above plant materials were taken out in a presterilized Petri plate, placed in the aseptic condition of Laminar air flow cabinet. Here they were treated with $0.1 \%$ $\mathrm{HgCl}_{2}$ for two minutes in another conical flask. During this the flask was manually shaken vigorously. Materials were transferred in another conical flask containing sterilized distilled water. This was done thrice by changing the water. Shaking was done during this to remove even the trace of the adhering chemical.

The mature leaves, young leaves and internodal segments were cut with the help of pre-sterilized sharp blade. They were stored at low temperature wrapped in presterilized and moistened cloth.

\section{Preparation of Culture Media}

All the chemicals, plant growth regulators, used in these experiments were purchased from the suppliers of HiMedia products. The basal medium was used as formulated by Murashige and Skoog (1962) desired amounts of inorganic, micro and macro salts, the iron, and organic compounds were taken from the stock solutions, prepared earlier.

Desired concentrations of Auxin (2,4-D) and Cytokinin (Kinetin) here, 2,4-D, 0.5, 1.0 and $1.5 \mathrm{mg} / \mathrm{l}$ and Kinetin $0.2,0.3$ and $0.4 \mathrm{mg} / 1$ were added in the medium in three different sets. The agar $0.8 \%$ was used as gelling agent. The $\mathrm{pH}$ was adjusted to 5.8, before autoclaving, 30 $\mathrm{ml}$ above culture medium was dispensed in $250 \mathrm{ml}$ culture flask each. They were plugged with cotton plugs and wrapped with Aluminum foil to avoid wetting of the plugs during autoclaving. Autoclaving was done at $15 \mathrm{lb}$ pressure for 18-20 minutes. The temperature was expected to be $121^{\circ} \mathrm{C}$ at this pressure. All the culture flasks along with culture medium were allowed to cool at room temperature and then stored at low temperatures. They were used for inoculation after 3 days. Cultures showing any contamination were discarded after autoclaving.

\section{Inoculation of the Explants}

Actually media were prepared before the explants were collected and sterilized for inoculation. All the tools to be used in inoculation such as forceps, scalpel, blade, scissor beakers and Petri plates were also autoclaved prior to their use. Inoculation was done in the aseptic conditions of Laminar air flow cabinet. $70 \%$ ethanol was used for sterilization of forceps and needles after each inoculation. Before removing of the plug from the culture flask it was heated above the spirit lamp and the leaf cut into small segment, the internodal segment were carefully placed on the surface of the culture and the mouth was properly plugged. Each experiment was repeated thrice, and each time there were 20 cultures. The inoculated culture flasks were incubated in the culture room where the temperature was controlled at $26 \pm 1^{\circ} \mathrm{C}$, relative humidity at $63-68 \%$ and the light at 3000 lux. Cultures were observed on an alternate day, flasks showing contamination were taken out and discarded after autoclaving.

The day after which callus was initiated, percentage of explants responding for it, colour of the calli etc. were noted. Explants showing swelling was also noted and percentage of response was calculated. The data obtained for different treatments have been placed in the tables 1-3. 
Impact of coconut milk on biomass production of callus in subculture was also studied. Fresh coconut milk was extracted from green fruits. This was deproteinated after boiling. It was filtered through the muslin cloth and filtrate was stored at low temperature. Subculture of calli was done in the same medium in which better growth was obtained. Here, the coconut milk was added at $0.5 \%, 1.0 \%$ and $1.5 \%$. The period of incubation was fixed that was 3 weeks. The colour of the callus, its diameter, weight of calli and percentage of response was calculated.

The data obtained were placed in table 4 . Callus with coconut milk was used as control. $200 \mathrm{mg}$ fresh callus was inoculated in culture medium without coconut milk was taken as control.

\section{RESULTS AND DISCUSSION}

Data collected on the basis of experiments and observations have been presented in tables 1-4 and graph 1 $\& 2$. From the table it may be noted that among the explants, mature leaf was found more responsive with respect to callus induction. When inoculated in MS +0.5 $\mathrm{mg} / \mathrm{l}$ 2,4-D + $0.2 \mathrm{mg} / \mathrm{l} \mathrm{Kinetin}$ the percentage of response was 68.25 , followed by the internodal explants that was $62.72 \%$. Lowest percentage of response was observed in young leaf explants which was $52.38 \%$ only. This pattern of response for callusing was also found in case of cultures in MS + $1.0 \mathrm{mg} / \mathrm{l} 2,4-\mathrm{D}+0.3 \mathrm{mg} / \mathrm{l}$ Kinetin. Here the percentage of response in the adult leaf explants was $73.65 \%$ followed by internodal explants $68.54 \%$ and young leaf explants $64.32 \%$. Maximum percentage of response for callus induction among the mature leaf explants was also observed in MS + $1.5 \mathrm{mg} / 1$ 2,4-D + $0.4 \mathrm{mg} / \mathrm{l}$ Kinetin which was $90.34 \%$ followed by internodal explants $78.50 \%$ and young leaves $72.46 \%$ respectively. It may be noted from the table that most suitable concentrations of plants growth regulators for the induction of callus in three different explants was MS + $1.5 \mathrm{mg} / 1$ 2,4-D + $0.4 \mathrm{mg} / \mathrm{l}$ Kinetin, followed by MS + $1.0 \mathrm{mg} / 1$ 2,4-D + $0.3 \mathrm{mg} / 1$ Kinetin. Lowest percentage of response with respect to callus induction was noted in case of MS + $0.5 \mathrm{mg} / 1$ 2,4-D + 0.2 $\mathrm{mg} / \mathrm{l}$ Kinetin. Time taken for initiation of callus was the maximum 14 days for young leaf used as explants, in the medium where lowest percentage of response was noted.

Tables 1: Medium - MS + 0.5 mg/l 2,4-D + 0.2 mg/l Kinetin

\begin{tabular}{|c|c|c|c|c|}
\hline Explants & \% Swelling & \% of Callus induction & Time taken & Colour of the callus \\
\hline Young leaf & 66.54 & 52.38 & 14 days & Cream white \\
\hline Matured leaf & 74.38 & 68.25 & 12 days & Greenish \\
\hline Internode & 71.65 & 62.72 & 12 days & Yellow green \\
\hline
\end{tabular}

Tables 2: Medium - MS + 1.0 mg/l 2,4-D + 0.3 mg/l Kinetin

\begin{tabular}{|c|c|c|c|c|}
\hline Explants & \% Swelling & \% of Callus induction & Time taken & Colour of the callus \\
\hline Young leaf & 68.75 & 64.32 & 13 days & Dull white \\
\hline Matured leaf & 79.45 & 73.65 & 11 days & Green white \\
\hline Internode & 72.80 & 68.54 & 11 days & Yellow white \\
\hline
\end{tabular}

Tables 3: Medium - MS + 1.5 mg/l 2,4-D + 0.4 mg/l Kinetin

\begin{tabular}{|c|c|c|c|c|}
\hline Explants & \% Swelling & \% of Callus induction & Time taken & Colour of the callus \\
\hline Young leaf & 78.25 & 72.46 & 11 days & white \\
\hline Matured leaf & 94.68 & 90.34 & 9 days & Green white \\
\hline Internode & 88.72 & 78.50 & 10 days & Yellow white \\
\hline
\end{tabular}


Tables 4: Medium - MS + $1.5 \mathrm{mg} / \mathrm{l}$ 2,4-D + $0.4 \mathrm{mg} / \mathrm{l}$ Kinetin

\begin{tabular}{|c|c|c|c|c|}
\hline Coconut Milk & $\begin{array}{c}\text { Period of incubation 3 } \\
\text { weeks (Colour) }\end{array}$ & $\begin{array}{c}\text { Diameter of calli } \\
(\mathrm{mm})\end{array}$ & $\begin{array}{c}\text { Weight of the calli } \\
(\mathrm{mg})\end{array}$ & \% Response \\
\hline$+0.5 \%$ & Greenish & 32.45 & 938.74 & 88.25 \\
\hline$+1.0 \%$ & Dark Green & 34.80 & 948.65 & 92.54 \\
\hline$+1.5 \%$ & Dark Green & 36.38 & 959.72 & 94.30 \\
\hline Control & Green White & 23.72 & 680.54 & 81.40 \\
\hline
\end{tabular}

Initial weight of callus inoculated was $200 \mathrm{mg}$. Data are mean of three replicates, each containing 20 cultures.

Graph 1: Showing \% Swelling, \% of Callus induction \& time taken with different explants at different concentrations of 2, 4-D and KN supplemented with MS Medium for callus induction

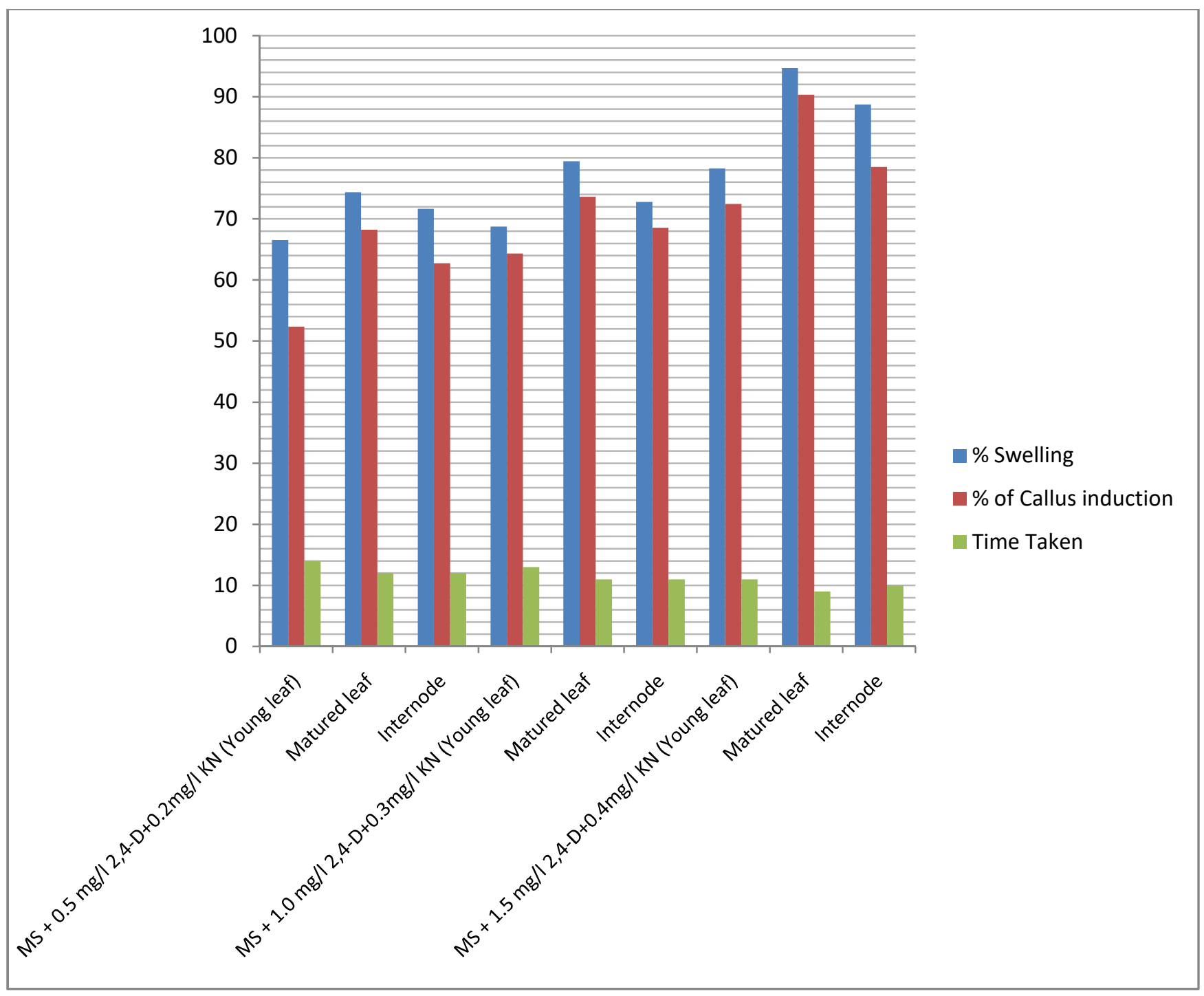




\section{Graph 2: Showing diameter of calli, weight of calli and \% response in culture supplemented with different concentration of Coconut milk.}

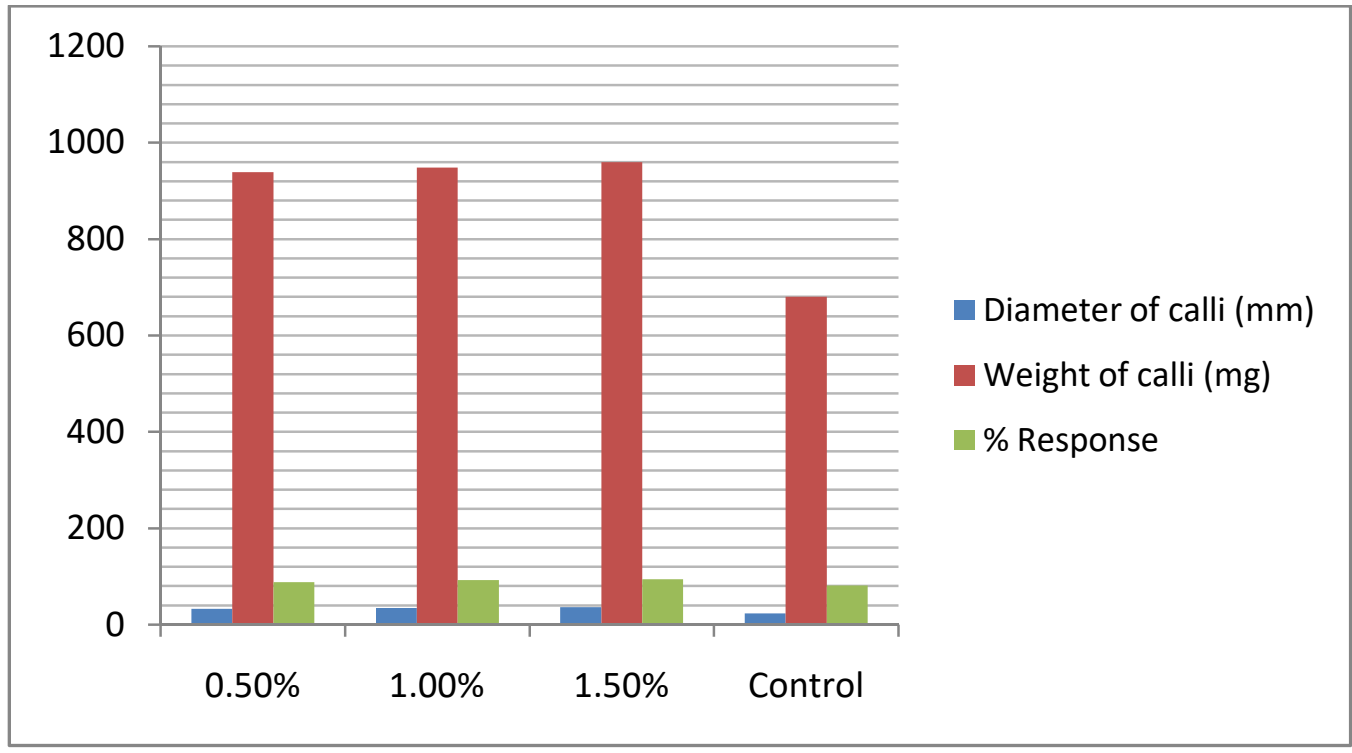

Similarly, minimum periods taken for callus initiation was taken by mature leaf explants that was 9 days in the medium where maximum response was found. This was followed by the internodal explants that were 10 days. Young leaf explants took 11 days for initiation in the medium.

Experiments were also done to evaluate different concentrations of coconut milk on growth and fresh weight of the callus. Data were presented in the table 4 . From the table it was clear that $\mathrm{MS}+1.5 \mathrm{mg} / 1$ 2,4-D $+0.4 \mathrm{mg} / \mathrm{l}$ Kinetin +1.5 Coconut milk, induced maximum growth where the diameter was $36.38 \mathrm{~mm}$, the fresh weight was $959.72 \mathrm{mg}$ and the response was $93.30 \%$ after three weeks of inoculation of similar amount of callus in the control as well as in $1.0 \%$ and $0.5 \%$ coconut milk.

This was followed by MS $+1.5 \mathrm{mg} / 1+0.4 \mathrm{mg} / \mathrm{l}$ Kinetin, where the diameter was 34.80 and in $0.5 \%$ Coconut milk it was only 32.45 . The fresh weight was $948.65 \mathrm{mg}$ and $938.74 \mathrm{mg}$ respectively. The percentage of response was 92.54 and $88.25 \%$. From the table it was observed that in the same medium without coconut milk the growth was $23.72 \mathrm{~mm}$, the weight was $680.54 \mathrm{mg}$ and the response was $81.40 \%$.

\section{DISCUSSION}

In the present work, it was found that mature leaf explants revealed highest frequency of callus induction than rest of the two explants that were young leaves and the internodes. Among different concentrations of 2, 4-D at 1.5 $\mathrm{mg} / \mathrm{l}$ and $0.4 \mathrm{mg} / \mathrm{l} \mathrm{Kinetin}$ gave better results than that of the other concentrations. Woodward and Bartel, 2005; Sakakibara, 2006; reported that auxins and cytokinins in the culture medium regulate various aspects of plant cell dedifferentiation and differentiation. Generally, auxins are used for callus induction and proliferation and both auxins and cytokinins are required for redifferentiation of callus into organized cell (Wang et al., 2008).

Callus induction has been reported by different workers in different medicinal plants. Sharath et al., (2007) reported that 2,4-D at different concentrations induced callus in leaf explants of Bacopa monnieri. They found that both the lower $0.25 \mathrm{mg} / 1$ and the higher $2.0 \mathrm{mg} / 1$ concentrations had lower effect on callogenesis. Das and Mandal (2010) observed enhanced rate of callus induction in Stevia rebaudia Bert in the MS medium supplemented with $2.0 \mathrm{mg} / 1$ 2,4-D + $0.5 \mathrm{mg} / 1 \mathrm{BAP}$.

Rout et al., (2011) induced callus in leaf explants of Bacopa monnieri in MS + $2.0 \mathrm{mg} / \mathrm{l} \mathrm{BAP}$ alone and MS + $2.0 \mathrm{mg} / \mathrm{l} \mathrm{BAP}+1.0 \mathrm{mg} / \mathrm{l} \mathrm{NAA}$. Similar result was obtained with $\mathrm{MS}+1.5 \mathrm{mg} / \mathrm{l} \mathrm{Kinetin}+$ NAA. All these findings are 
in agreement with the findings of present work as also a combination of 2,4-D + Kinetin gave better result with respect to callus induction in leaf explants when cultured in MS medium along with the above plant growth regulators.

Osman et al., (2013) used MS + $1.0 \mathrm{mg} / 1$ 2,4-D + $0.3 \mathrm{mg} / \mathrm{l} \mathrm{BAP}$ and found $100 \%$ callus induction in the leaf explants of Lycium barbatum L., an important herb used in traditional Chinese medicine. Kalsaitkar et al., (2014) induced callus in leaf explants of Bacopa monnieri in MS + 2,4-D + Kinetin, at different concentration. Panathulu et al., (2014) found maximum induction of callus in leaf explants of Centella asiatica in MS $+2.0 \mathrm{mg} / 1$ 2,4-D + $0.5 \mathrm{mg} / \mathrm{l}$ BAP.

Priya Dharishini et al., (2014) found that even 0.4 $\mathrm{mg} / 1$ 2,4-D when supplemented in MS medium could induce callus in leaf explants of Bacopa monnieri. Thangavel et al., (2014) reported that when leaf explants of Decalepis hamiltonii was cultured in MS $+10.0 \mu \mathrm{m}$ 2,4-D , there was maximum callus induction. Mehta (2017) reported that MS $+1.5 \mathrm{mg} / 1$ 2,4-D, gave better result with respect to callus induction in leaf explants of Bacopa monnieri L. In the present work also leaf explants when cultured in $\mathrm{MS}+1.5 \mathrm{mg} / \mathrm{l}$ 2,4-D + $0.4 \mathrm{mg} / \mathrm{l}$ Kinetin gave better response with respect to callus induction as here the highest percentage of explants induce calli and the time taken for callus induction was also the minimum. Therefore, findings of the present work corroborate with the findings of the above workers.

For higher biomass production of callus, different adjuvant has been used by different workers. Siva et al., (2009) used different percentage of coconut milk in medium containing plant growth regulators that induce callus in Oldenlandia umbellate leaf explants. They concluded that biomass of calli increased with higher growth rate than that of the calli cultured in control. The weight of calli varied according to the concentration of coconut milk supplemented in the medium. Findings of the present work are with agreement of the aforesaid findings as here also the biomass varied along with the concentration of the coconut milk, added in the medium.

Das and Mandal (2010) reported that if amino acids are supplemented in the medium, used for sub culture of calli, the rate of proliferation of the calli used for sub culture. They noted that among the amino acids used glutamine supplemented at the rate of $50 \mathrm{mg} / \mathrm{l}$ gave best result.

Here the percentage of response was 88.09 and the weight increased considerably than that of the control. These workers also used casein hydrolysate as an adjuvant to observe its effect on biomass production of calli, cultured in the suspension culture.

Thangavel et al., (2014) subcultured the calli raised from leaf disc of Bacopa monnieri L. in MS medium supplemented with $6 \mu \mathrm{M}$ NAA $+2.0 \mu \mathrm{M}$ BAP $+10 \%$ coconut milk $+2 \%$ Sucrose $+1.2 \%$ Agar $+0.05 \%$ Polyvenylpyrrolidone and found that $0.5 \mathrm{~g}$ of callus after 20 days of inoculation became $2.9 \mathrm{~g}$. In the present work also in $\mathrm{MS}+1.5 \mathrm{mg} / \mathrm{l} 2,4-\mathrm{D}+0.4 \mathrm{mg} / \mathrm{l} \mathrm{KN}+1.5 \%$ coconut milk, $200 \mathrm{mg}$ callus became $959.72 \mathrm{mg}$. Therefore, present finding corroborates with the findings of above workers.

\section{CONCLUSION}

Experiments for induction of calli in different explants of Bacopa monnieri were performed. It was found that among the explants, mature leaves were much responsive than the young leaves and the internodal explants.. Likewise, MS + $1.5 \mathrm{mg} / 1$ 2,4-D $+0.4 \mathrm{mg} / 1 \mathrm{KN}$ was most favorable culture conditions for callus induction. The calli were subcultured for biomass production. Here $\mathrm{MS}+1.5 \mathrm{mg} / \mathrm{l}$ 2,4-D +0.4 mg/l KN $+1.5 \%$ Coconut milk favoured much faster growth. Enhanced biomass may be utilized for the extraction of the important secondary metabolite, Bacoside A, which is being used in the production of memory enhancing capsules.

\section{ACKNOWLEDGEMENT}

Author is grateful to the Head, Department of Botany, B. R. A. Bihar University, Muzaffarpur for their kind support in the form of infrastructure facilities of the Department to conduct the study.

\section{REFERENCES}

Ahmed Abdul B.A., Rao A.S., Mandali V., Rao and Taha R.M., 2011. Effect of picloram, additives and plant growth regulators on somatic embryogenesis of Phyla nodiflora (L.) Braz. Arch. Biol. Technol., 54(1):7-13.

Ardkani M.D., Kazem K. and Soghra R., 2017. The effect of some plant growth regulators (PGRs) coconut 
milk and casein hydrolysate on somatic embryogenesis of Stevia an antidiabetic medicinal plant. Electronic Journal of Biology, 13(4): 343347.

Arumugam N. and Bhojwani S.S., 1990. Somatic embryogenesis in tissue culture of Podophyllum hexandrum. Can. J. Bot., 68: 487-492.

Bahadur B., Janardan Reddy K.H. and Rao M.L.N., 2007. Medicinal plants an overview: Advances in Medicinal Plants. Janardan Reddy K, Bahadur B, Bhadraiah B., Rao MLN, Eds: 14-36.

Chaturvedi H.C., Jain M. and Kidwai N.R., 2007. Cloning of medicinal plants through tissue culture: A review. Ind. Journ. Of Exp. Biol., pp.937-948.

Chaudhary D.K., Parmar D., Kakkar P., Shukla R., Seth P.K. and Srimal R.C., 2002. Antistress effect of Bacopa monnieri modulation of Hsp 70 expression superoxide dismutase arid $\mathrm{P} 450$ activity in rat brain. Phytotherapy Research, 16(7): 639-645.

Das A. and Mandal N., 2010. Enhanced development of embryogenic callus in Stevia rebaudiana Bert. by additives and amino acids. Biotechnology, 9: 368372 .

Jayakumar S. and Lingam R.R., 2013. Influence of additives on enhanced in vitro shoot multiplication of Orthosiphon aristatus. Scientia Biologicae 5:338-345.

Joshi A.G, Pathak A.R., Sharma A.M. and Singh S., 2010. High frequency of shoot regeneration on leaf explants of Bacopa monnieri. Environmental and Experimental Biol., 8:81-84.

Juan L., Lihua W., Jing L. and Junhui W., 2010. Effect of different plant growth regulators on callus induction in Catalpa bungei. Afr. J. Agric. Res., 5: 2699-2704.

Kalsaitkar, Priya, Tana J., Anand K., Akre S., Warade C. and Gandhare N., 2014. Silver nano particles induced effect on in vitro callus production in Bacopa monnieri. Asian J. of Biological and Life Sciences, 3(3): 167-172.

Kaur J., Nautiyal K. and Pant M., 2013. In vitro propagation of Bacopa monnieri (L.) A medicinally priced herb. Int. J. Curr. Microbiol. App. Sci., 2(8): 131-138.

Khattak M.S.K., Abiri R., Alireza V., Atabaki N., Shariat M., Talei D. and Maziah M., 2017. Somatic embryogenesis and in vitro regeneration of Rice (Oryza sativa L.) cultivar under one step and multi step salinity. J. of Plant Breed \& Genet, 5(2): 75 89.

Kumari R., Priyadarshini M., Kumari A. and Shukla L.N., 2014. In vitro mass multiplication of Bacopa monnieri (L.) an endangered and valuable medicinal herb. Indian J. Sci. Res., 7(1): 12481253

Madhulkar D., Patade P.S. and Singh S.N., 2011. DMSO induced product recovery of Bacoside $\mathrm{A}$ in cell suspension culture of Bacopa monnieri L. Int. J. of Pharmaceut. Sci. and Res., 45: 3006-3009.

Martin K.P., 2004. Benzyladenine induced somatic embryogenesis and plant regeneration of Leptadenia reticulate. Biol. Plant, 48(2): 285-288.

Mehta A., 2017. Effect of plant growth regulators on callus multiplication and in vitro plant regeneration in Bacopa monnieri L. Int. J. of Med. Plant Res., 6(5): 337-345.

Monge G.G., Andres M., Gatica A. and Melara M.V., 2008. Somatic embryogenesis, plant regeneration and acemannan detection in Aloe. Agronomis Costarricene, 32(2): 41-52.

Murashige T. and Skoog F., 1962. A revised medium for rapid growth and bioassays with tobacco tissue cultures. Physiol. Plant, 15:473-497.

Osman N.I., Awal A., Sidik N.J. and Abdullah S., 2013. Callus induction and somatic emryogenesis, from leaf and nodal explants of Lycium barbatum (L.). Biotechnology, 12: 36-45.

Ranjan R., Kumar S. and Singh A.K., 2018. An efficient in vitro propagation protocol of local germplasm of Bacopa monnieri (L) found in Bihar: A plant with wide variety of medicinal properties. J. of Pharmacog and Phytochemistry, 7(1): 1803-1807. 
Rani G. and Grover I.S., 1999. In vitro callus induction and regeneration studies in Withania somnifera. Plant Cell Tissue Organ Cult., 57: 23-28.

Rao S.B., Sharan S.V., Seema C., Vanigadda S.A. and Vangalapati M., 2011. A review on pharmacological studies of Bacopa monnieri. J. Chem. Bio. Phy. Sci., 1(2): 250-259.

Rout J.R., Sahoo S.L., Sethi S.S. and Das R., 2011. Standardization of an efficient protocol for in vitro clonal propagation of Bacopa monnieri an important medicinal plant. J. of Agricultural Technology, 7(2): 289-299.

Sakakibara H., 2006. Cytokinin: Activity, biosynthesis and translocation. Annu. Rev. Plant Biol., 57: 431-449.

Showkat P., Zaidi Y., Asghar S. and Jamaluddin S., 2010. In vitro propagation and callus formation of Bacopa monnieri (L.) Penn. Plant Tissue Culture \& Biotechnology, 20(2): 119-125.

Siva R., Rajsekaran C. and Mudgal G., 2009. Induction of somatic embryogenesis and organogenesis in Oldenlandia umbellate L., a dye-yielding medicinal plant. Plant Cell Tissue Organ Cult., 98: 205-211.

Srivastva P., Tiwari K.N. and Srivastva G., 2017. Effect of different carbon sources on in vitro regeneration of Brahmi, Bacopa monnieri L. An important memory vitalizer. J. of Med. Plants. Stu., 5(3): 202-208.
Subashri B.J. and Kolipillai Y., 2012. High frequency regeneration of Bacopa monnieri plant callus derived from internode. Int. J. Pharma \& Biosci., 4(1): 263-266.

Subhashri B. and Pillai Y.J.K., 2014. In vitro regeneration of Bacopa monnieri (L.) Pennel - A multipurpose medicinal plant. Int. J. of Pharmacy \& Phamaceut. Sci., 6(4): 559-562.

Sundriyal A., Rawat D.S. and Singh A.K., 2013. Tissue culture, phytochemical \& pharmacological study of Bacopa monnieri. Asian J. Biochem. Pharm. Res., 3(1): 243-260.

Thangavel K., Ravichandran P., Ebbie M. and Manimekalai $\mathrm{V}$., 2014. In vitro microrhizome production in Decalepis hamiltonii. African J. of Biotechnology, 13(1): 1308-1313.

Tsay Hsin-Sheng and Agarwal D.C., 2005. Tissue culture technology of Chinese medicinal plant resource in Taiwan and their sustainable utilization. Int. J. Appl. Sci. \& Engin., 3(3): 215-223.

Wang W., Xhao X., Zhuang G. Wang S. and Chen F., 2008. Simple hormonal regulation of somatic embryogenesis and or shoot organogenesis in caryopsis culture of Pogonatherum panicum, Plant Cell Tiss. Org. Cult., 95: 57-67.

Woodward A.W. and Bartel B., 2005. Auxin: Regulation, action and interaction. Annals of Botany, 95(5): 707-735. 